\title{
ENTREVISTA COM GIOVANNI REALE PARA A EDIÇÃO COMEMORATIVA DA REVISTA EDUCAÇÃO E FILOSOFIA ${ }^{1}$
}

\section{BREVE APRESENTAÇÃO SOBRE GIOVANNI REALE}

Em fevereiro de 2006, num congresso de filosofia antiga na belíssima cidade de Como, extremo norte da Itália, o professor que conduzia os trabalhos do dia, com um senso de humor que contrastava com o rigoroso frio do inverno europeu, nos apresentou Giovanni Reale com as seguintes palavras: "Vos apresento aquele que não precisa de ser apresentado, pois todos que se dedicam à filosofia, em qualquer parte, conhecem o seu trabalho!". Não fossem ditas por Enrico Berti em uma ocasião na qual estavam reunidos alguns dos maiores platonistas vivos, tal comentário poderia ter soado, quando não exagerado, ao menos pouco comedido. Em verdade, todavia, este é um exemplo do merecido reconhecimento que Giovanni Reale conquistou nas décadas de incansável dedicação à pesquisa em filosofia e à formação de discípulos de relevância e competência internacionais, motivo pelo qual o homenageamos - e, ao mesmo tempo, somos homenageados - com a publicação de uma sua entrevista exclusiva para a edição de aniversário da nossa revista Educação e Filosofia.

Permitam-nos contrariar o prof. Berti fazendo uma brevíssima apresentação do entrevistado. Giovanni Reale nasceu em Candia Lomellina (Pavia), no dia 15 de abril de 1931. Formou-se pela Università Cattolica del Sacro Cuore di Milano e desenvolveu suas pesquisas de pós-graduação na Alemanha, país no qual estabeleceu uma série de fecundos contatos, essenciais para a sua ulterior formação de estudioso (em especial com Hans Krämer e Konrad Gaiser, fundadores da famosa Escola de Tübingen, dedicada ao

1 Entrevista conduzida e traduzida por Dennys Garcia Xavier, doutorando em Storia della Filosofia, Università degli Studi di Macerata (Itália). Bolsista de doutorado pleno no exterior pela Coordenação de Aperfeiçoamento de Pessoal de Nível Superior (CAPES), sob orientação do Prof. Maurizio Migliori. E-mail: dennysgx@gmail.com 
platonismo). Depois de um período como professor de Liceu equivalente ao nosso ensino médio - Reale tornou-se professor de Storia della Filosofia na Università di Parma. Pouco depois, assumiu na Università Cattolica di Milano a cadeira de Storia della Filosofia Antica e ali permaneceu por um longo e frutuoso período. Atualmente, é professor da Faculdade de Filosofia da Universidade San Raffaele di Milano, onde nos concedeu a entrevista.

Vários são os sistemas filosóficos aos quais Reale dedicou atenção. De modo especial, porém, seus estudos mais importantes vão de Sócrates, Platão e Aristóteles, até o tardo-helenismo e a filosofia cristã. Dono de erudição invejável, colocou em crise uma série de interpretações consideradas por muitos atemporais - como, para citarmos dois notórios exemplos, a histórico-genética proposta por Werner Jaeger para a leitura de Aristóteles e a de Eduard Zeller, com o seu Plotino de perfil panteísta-imanentista -, fato que, naturalmente, fez dele alvo tanto de grande admiração quanto de severas críticas (algumas das quais notadamente, por assim dizer, pouco científicas!).

Nesta breve, mas reveladora entrevista, Giovanni Reale fala em tom informal de parte de sua carreira acadêmica, de alguns dos desafios que enfrentou durante seus anos como estudante e esclarece aspectos da sua vida - inclusive pessoal - que, ainda hoje, suscitam não pouca polêmica. Uma entrevista que nos revela um intelectual brilhante, ciente do trabalho que desenvolve em prol da formação do homem enquanto tal e da busca pela Verdade. Não um filodoxo, um estudioso que se diverte em citar autores para, amparando-se em "signos estranhos" - para dizer com Platão -, velar ausência de substância, mas, ao contrário, alguém que busca na história da filosofia princípios e valores para viver melhor, como homem e como ser social. Um estudioso, em suma, que de forma emblemática, sabe pôr em prática aquilo que extrai dos livros (uma raridade, vale dizer, no mundo cada vez mais "técnico-burocrata" da Academia).

Aproveitamos esta importante ocasião para agradecer publicamente a gentil contribuição do Prof. Maurizio Migliori (Università degli Studi di Macerata, Itália) que, na condição de discípulo de primeiro grau de Giovanni Reale, viabilizou esta entrevista. Vamos a ela. 


\section{ENTREVISTA COM GIOVANNI REALE}

XAVIER: Professor Reale, o senhor tem uma brilhante carreira acadêmica, os seus escritos foram traduzidos em várias línguas e, ainda, desfruta do respeito de pesquisadores que representam as mais diversas correntes de interpretação no mundo universitário. Obviamente, esta carreira foi construída em um longo percurso de estudos, leituras, viagens etc. Gostaria de saber qual foi o seu primeiro contato com a filosofia e o porquê de tê-la escolhido como objeto de estudos.

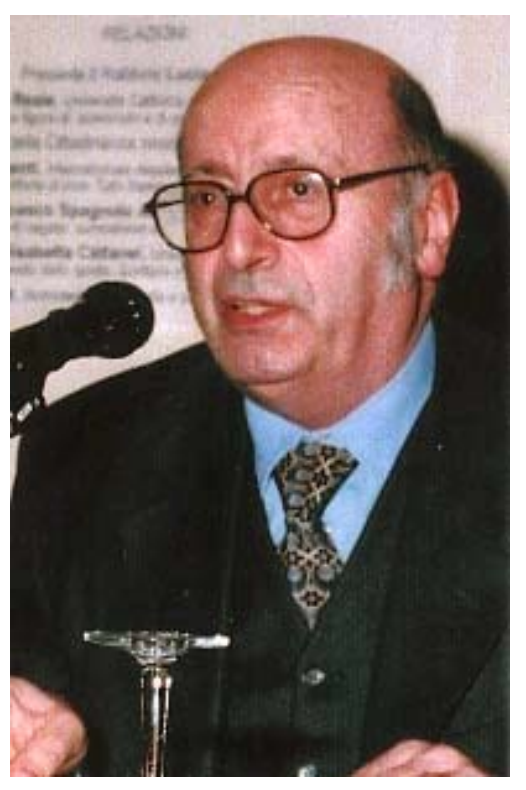

homens. Própria dos homens é, ao invés, a "filosofia", o amor pela "sofia" e a pesquisa dedicada a ela. O homem é um homo viator e o que pode fazer é exatamente buscar a Verdade, ainda que não a encontre jamais na sua inteireza.

Por isso, escolhi especializar-me não em filosofia teorética e sistemática, mas em história da filosofia, para descobrir os vários modos a partir dos quais o homem construiu os vários sistemas, na sua contínua viagem sobre a via da Verdade. 
XAVIER: Parte do seu percurso formativo foi feito na Alemanha. Qual é a importância de um período de estudos no exterior? O senhor acredita que, ainda hoje, com o advento da internet, com a difusão dos encontros internacionais, os léxicos digitais e todos os recursos tecnológicos disponiveis, este tipo de experiência seja ainda determinante?

REALE: Os anos que passei na Alemanha, em Marburg e em München, foram essenciais para mim, não só do ponto de vista da aprendizagem de um sólido método científico (a Alemanha era então o mais importante país no que diz respeito aos estudos sobre o pensamento antigo), mas também para a minha formação espiritual. Recordo que então (1954-1957), as relações dos alemães com os italianos eram muito tensas, já que os italianos (em função dos acontecimentos ligados à Segunda Guerra Mundial e das suas conclusões) eram considerados, se não traidores, pelo menos homens não confiáveis.

Lembro um particular muito significativo: dado que era laureado, fui admitido à mesa com os professores. Os estudantes que chegavam atrasados precisavam pedir ao tutor permissão para comer. Com até cinco minutos de atraso, em geral, a permissão era dada, caso contrário, não. Além disso, quando o estudante retardatário sentava-se no seu lugar, todos os colegas deviam expressar a ele desaprovação, arrastando os pés no chão de um modo específico. À mesa, em minha presença, falavam freqüentemente muito mal dos italianos. E um dia, depois que um dos professores havia ultrapassado os limites da decência nas suas críticas, pedi a palavra e disse: "vocês alemães falam tão mal dos italianos...mas quantas vezes vocês foram à Italia e ali comeram?" A resposta foi terrível: "sim, ali freqüentemente comemos, mas vocês arruinaram nossos estômagos!".

Devo dizer, todavia, que depois de ter sido submetido a diversas provas, o diretor cedeu-me a chave da biblioteca para que, quando necessário, eu pudesse consultar os livros também fora do horário normal de funcionamento. Com base no que aprendi com os alemães naqueles anos, pude estabelecer excelentes contatos com Hans Krämer, Konrad Gaiser, Werner Beierwaltes, Thomas 
Szlezàk e, por último, também com Hans-Georg Gadamer.

No que diz respeito à Internet e aos vários instrumentos multimídia, são coisas extraordinárias que simplificam e resolvem uma grande quantidade de problemas, mas não ensinam a ter contato com homens, e não fazem crescer o homem enquanto tal.

XAVIER: O senhor conhece várias línguas. Quando começou a estudálas? Qual é a sua importância para o estudo da filosofia?

REALE: Uma língua não é apenas um instrumento asséptico de comunicação, mas é expressão de uma cultura com todas as suas implicações e conseqüências. Por isso, só com a língua materna, o estudioso fica, sob certos aspectos, um isolado. E é isso o que acontece, por exemplo, com certos estudiosos da área cultural da língua inglesa. Assim como o inglês é uma língua universal, que a maior parte das pessoas entende, muitos daqueles estudiosos deixam de estudar outras línguas, gerando conseqüências facilmente imagináveis. Comecei a estudar línguas no ginásio e não parei mais, sobretudo o francês e o alemão.

XAVIER: O senhor é co-autor e divulgador de um novo paradigma interpretativo do pensamento platônico (a assim denominada "escola de Tübingen-Milão") que valoriza as "Doutrinas não-escritas" de Platão. Por quais motivos o senhor aderiu a este novo modo de ler Platão?

REALE: O primeiro impacto que sofri a propósito da interpretação de Platão proposta pela Escola de Tübingen aconteceu depois da leitura de um grande livro de $\mathrm{H}$. Krämer, Areté bei Platon und Aristoteles. ${ }^{2} \mathrm{O}$ livro contrariava a tese de $\mathrm{H}$. Cherniss, então muito difundida na Itália (aliás, em 1974 foi publicada a tradução italiana de um sintético livro di Cherniss, L'enigma dell'Accademia Antica ${ }^{3}$ ).

2 KRÄMER, H. Areté bei Platon und Aristoteles. Heidelberg: Carl Winter, 1959. (N. do T.)

3 CHERNISS, H. L. The Riddle of the Early Academy. Berkeley; Los Angeles: University of California Press, 1945. Traduzione italiana di L. Ferrero: L'enigma dell'accademia antica, Florença, 1974. (N. do T.) 
A partir dali, perguntei ao próprio Krämer se aceitava escrever um livro sintético, acessível não apenas aos especialistas em filosofia antiga, mas a todos os cultores da filosofia, sobre a interpretação da Escola de Tübingen, que eu mesmo traduziria. Krämer aceitou prontamente e escreveu o volume Platone e $i$ fondamenti della metafisica. ${ }^{4}$ Rigoroso cientista que é, quis controlar diretamente comigo cada palavra da tradução. E, nestes encontros (na Itália e na Alemanha), eu pedia continuamente que me fossem dadas as provas das várias afirmações, sobre a base de precisos documentos. Os documentos que me foram paulatinamente oferecidos se mostraram tão precisos (e, sob muitos aspectos, indiscutíveis), que lhe pedi para apresentá-los de forma sistemática no final do volume (com texto grego e tradução para o italiano). Como conseqüência, percebi a insustentabilidade da tese tradicional da "autarquia" dos diálogos e da impossibilidade de entender Platão lendo apenas os seus escritos e refutando o exame pormenorizado também da tradição indireta, justificada pelo próprio Platão nos seus autotestemunhos do final do Fedro e do excursus da Carta VII. Por isso, peguei esta estrada e tratei de percorrê-la de modo sistemático até o fim.

XAVIER: O senhor esperava a resistência dos pesquisadores a propósito deste novo paradigma interpretativo? A que se deve tal resistência?

REALE: A resistência verificada a propósito da tese da Escola de Tübingen - que apresentei como um verdadeiro e próprio paradigma hermenêutico alternativo àquele formulado na idade moderna a partir de Schleiermacher e que terminei por completar sobretudo sobre alguns pontos - é exatamente aquela que Kuhn demonstrou surgir todas as vezes em que é proposto, no âmbito das diversas pesquisas científicas, um novo paradigma alternativo àquele predominante.

Faço um exemplo particularmente eloquente: quando publiquei a primeira edição completa do meu livro Para uma nova

4 KRÄMER, H. Platone e i fondamenti della metafisica. Introduzione e traduzione di Giovanni Reale. Milano: Vita e Pensiero, 2001. (N. do T.) 
interpretação de Platão, ${ }^{5}$ os dois professores universitários de História da Filosofia Antiga mais influentes, do ponto de vista acadêmico, me convidaram para um almoço para dizer que deveria ter jogado o livro num moedor, porque teriam proibido a sua adoção, na medida em que "poluía" o puro pensamento de Platão. Mas o êxito da obra julga os juízes de forma irreversível. Em 2003, publiquei a vigésima-primeira edição e, neste ínterim, o livro foi traduzido para o alemão, inglês, português, espanhol e tcheco. Ademais, já está em avançada fase de elaboração a tradução romena.

Os que mais aprovam a nova interpretação são os jovens. No entanto, são freqüentemente condicionados pelos seus mestres, alguns dos quais fazem de tudo para que mudem de rota, ainda que com métodos bem pouco científicos.

XAVIER: Fazendo um pequeno exercício de "futurologia", para o senhor, o novo paradigma da escola de Tübingen-Milão conseguirá impôr-se ao mundo da academia como um dia o fez aquele de Schleiermacher? Qual é o atual nível de aceitação ao novo paradigma entre os pesquisadores?

REALE: Depois de ter escrito o Para uma nova interpretação de Platão, escrevi também Platone: Alla ricerca della sapienza segreta, ${ }^{6}$ publicado em 1998 (com três edições no mesmo ano), e já transferido (pelo sucesso obtido) a uma coleção de livros de bolso. Acredito que o novo paradigma, tal como demonstro neste segundo livro, recebe conspícuo suporte das pesquisas sobre tecnologias da comunicação no mundo antigo. O predomínio da cultura da escrita e a superação da cultura da oralidade ocorria exatamente no arco de tempo da vida de Platão. E é propriamente na compreensão da dinâmica desta revolução cultural que conseguimos entender a posição adotada por Platão e as relações assumidas por ele a propósito da escrita e da oralidade.

5 REALE, G. Para uma nova interpretação de Platão. Tradução de Marcelo Perine. São Paulo: Loyola, 1997. (N. do T.)

6 REALE, G. Platone: Alla ricerca della sapienza segreta. Milano: Rizzoli, 1998. (N. do T.) 
XAVIER: Alguns estudiosos o acusam de propôr uma interpretação "hipermetafísica" de Platão, por causa da sua relação com o catolicismo. Como o senhor responde a acusações desta natureza? Poder-se-ia dizer que esta influência religiosa existe realmente na sua leitura de Platão?

REALE: Devo dizer que aqueles que sustentam tal tese não conhecem nem o catolicismo na sua verdadeira natureza, nem o modo no qual o vivo, como homem que crê verdadeiramente. Confundem a fé de um católico com uma ideologia. A minha fé não se mistura com questões científicas, quando as trato de modo rigoroso, também porque não creio que a ciência tenha as caracteristicas necessárias para adentrar o terreno da fé, dado os seus limites estruturais. A minha opinião a propósito de tal problema é a mesma do filósofo italiano Luigi Pareyson (Ontologia della libertà, 1995), qual seja, que ligar Deus e a fé em Deus com uma filosofia (grande que seja), significa cair em uma forma de antropomorfismo (ainda que bastante refinado): “Conceber Deus em termos conceituais significa definí-lo a partir de categorias elaboradas pela mente humana e atribuir-lhe propriedades que direta ou indiretamente são inerentes ao homem, ainda que extremamente refinadas e abstratas, e ainda que pensadas em sentido eminente e elevadas ao vértice. Neste sentido, conceber Deus como Ser, Princípio, Causa, Pensamento, Razão, Vontade, Pessoa, Bondade, Providência e, assim por diante, é sempre um kat'anthropon legein, que conferem a tais concepções da divindade um caráter substancialmente, ainda que veladamente, antropomórfico".

A minha fé religiosa está para além da minha interpretação de Platão, exatamente do ponto de vista estrutural, na medida em que ocupa um espaço que está para além da ciência.

XAVIER: Professor, qual é a importância da pesquisa em história da filosofia antiga num departamento de filosofia? Os outros momentos históricos do pensamento filosófico podem ser adequadamente entendidos sem uma correta compreensão da Antigüidade? 
REALE: Penso que a importância da história da Filosofia Antiga no âmbito de um departamento de filosofia e, por conseqüência, de uma graduação em filosofia seja absolutamente essencial.

Os gregos de fato nos deram o conceito de filosofia e muitos dos conceitos fundamentais que a filosofia moderna, assim como a contemporânea usam derivam dos conceitos criados pelo pensamento helênico. Sem a filosofia antiga faltam as bases do filosofar. Martin Heidegger dizia que a filosofia na Grécia nasceu grande. Talvez, poderíamos dizer, algumas vezes (sobretudo em certas tendências de hoje), que ela se mostra diminuída. Cito um caso verdadeiramente emblemático: J. Habermas sustenta a tese segundo a qual hoje a filosofia não é mais autorizada a intervir de modo direto nos problemas morais, ou seja, exatamente nos grandes problemas, e escreve: "Exatamente nas questões para nós mais relevantes, a filosofia se retira para uma espécie de meta-nível. Ela se limita a indagar as características dos processos de autocompreensão, fazendo abstrações do seu conteúdo. Mas que objeções poderíamos apresentar contra este abster-se bem justificado?". Mas, fazendo isto, tiramos da filosofia a sua consistência, e ela se dissolve. Os gregos são o antídoto curativo deste mal. E trata-se de um antídoto fortíssimo. Só quem compreendeu a filosofia antiga pode defender-se destes males da redução da filosofia à metodologia em todas as suas diversas formas.

XAVIER: Nos últimos anos, os estudos sobre filosofia antiga na América do Sul se desenvolveram devido ao empenho de diversos professores impetuosos e dedicados aos seus estudos e ao estreito contato com pesquisadores de outros continentes. Para o senhor, o que poderiam fazer para acelerar tal evolução?

REALE: O modo de acelerar a difusão e o estudo da filosofia antiga na América do Sul é um só: o do empenho e da paixão com os quais a difusão, como o senhor diz, se iniciou. Sem empenho e sem paixão não se conclui nada. 
XAVIER: As suas obras obtêm um grande sucesso editorial e este é um fato singular em um mundo particularmente restrito como o da pesquisa em filosofia. A que se deve tal sucesso?

REALE: Em primeiro lugar, estou espantado com o sucesso das minhas obras. São traduzidas em alemão, inglês, francês, espanhol, português, russo, polonês, servio-croata, ucraniano, romeno, tcheco, e estão em curso de tradução também em outras línguas. Comoveu-me, mais recentemente, o fato de que vários volumes da minha História da Filosofia Antiga ${ }^{7}$ sejam traduzidos até mesmo em esloveno (e a Eslovenia é uma nação de poucos habitantes).

Os motivos de tal sucesso me foram sugeridos pela tradutora russa (que traduziu em quatro volumes a obra Il Pensiero Occidentale, ${ }^{8}$ que escrevi com Dario Antiseri) e pelo tradutor polonês (que traduziu todos os volumes da História da Filosofia Antiga). À minha pergunta: "mas por qual motivo vocês fazem um trabalho tão complexo e cansativo, que leva embora muitos anos de suas vidas?". Responderam igualmente: "Procuramos as raízes das quais nascemos e que por muitas décadas ficaram no esquecimento". $\mathrm{O}$ tradutor polonês acrescentou ainda: "O marxismo criou nas almas um vazio total; para sair de tal situação, quem tem uma fé avança por esta estrada, quem não tem uma fé procura nos clássicos idéias fortes politicamente não comprometidas". A tradutora romena do meu livro Saggezza antica: terapia per i mali dell'uomo di oggi ${ }^{9}$ expressou-me conceito análogo dizendo: "Enfrento o cansaço tentando dar aos jovens romenos uma forte ajuda com o redescobrimento dos valores do pensamento clássico, na medida em que muitos deles passaram do 'niilismo marxista' ao 'niilismo consumista'". Não são as minhas idéias a ter sucesso, mas as idéias

7 REALE, G. História da Filosofia Antiga. Tradução de Marcelo Perine. São Paulo: Loyola, 1992. (N. do T.)

8 ANTISERI, D., REALE, G. Il pensiero occidentale dalle origini ad oggi. Brescia: La Scuola. (N. do T.)

9 REALE, G. Saggezza antica: terapia per i mali dell'uomo di oggi. Milano: R. Cortina, 1995. (N. do T.) 
dos clássicos, apresentadas por alguém que, como eu, acredita no seu valor.

O pintor Zeusi, questionado do porquê de ser tão lento ao compôr suas obras e de não se cansar de aperfeiçoá-las, respondeu: "porque estou pintando o eterno". Tucídides, na sua obra histórica, disse a mesma coisa; afirma, de fato, que isto que ele apresenta constitui "uma posse para o sempre", e Platão dizia que o filósofo é aquele que sabe olhar o eterno. Estou profundamente convencido de que as obras filosóficas dos antigos sejam verdadeiramente uma posse para o sempre. E considero que os leitores que me seguem pensem a mesma coisa (Platão é hoje o filósofo mais vendido, e não apenas no Ocidente).

XAVIER: Uma última pergunta: no prefácio da tradução italiana dos diálogos platônicos "Platone: Tutti gli Scritti" o senhor diz oferecer um livro que constitui uma ocasião de reflexão a todos os homens de cultura que acreditam ser necessário que o espírito humano se alimente dos melhores alimentos. Entre os bons alimentos que o senhor saboreou durante a sua vida dedicada à filosofia e à cultura em geral, qual foi o melhor?

REALE: O melhor alimento, naturalmente, foi aquele oferecido por Platão. Mas, a não grande distância, devo recordar a Metafisica de Aristóteles, à qual dediquei bem dez anos de trabalho. Também encontrei alimentos saborosos nos poetas. Hans-Georg Gadamer, no dia em que me concedeu a última entrevista, me dizia que ele aprendeu em alguns momentos mais com os poetas do que com certos filósofos, mesmo de grande reputação. Sou do mesmo parecer. Além dos três grandes poetas - Dante, Shakespeare, Goethe -, leio freqüentemente Rilke e Eliot...e com grande proveito! 



\section{INTERVISTA CON GIOVANNI REALE PER L'EDIZIONE COMMEMORATIVA DELLA RIVISTA EDUCAÇÃO E FILOSOFIA. ${ }^{1}$}

XAVIER: Professore Reale, Lei ha una brillante carriera accademica, $i$ Suoi scritti sono stati tradotti in varie lingue e gode del rispetto dei ricercatori che rappresentano le più diverse correnti d'interpretazione all'interno del mondo accademico. Ovviamente questa carriera è stata costruita in un lungo percorso di studi, letture, viaggi, ecc. E a questo proposito, vorrei sapere qual è stato il Suo primo contatto con la filosofia e perché Lei ha scelto di occuparsi di filosofia.

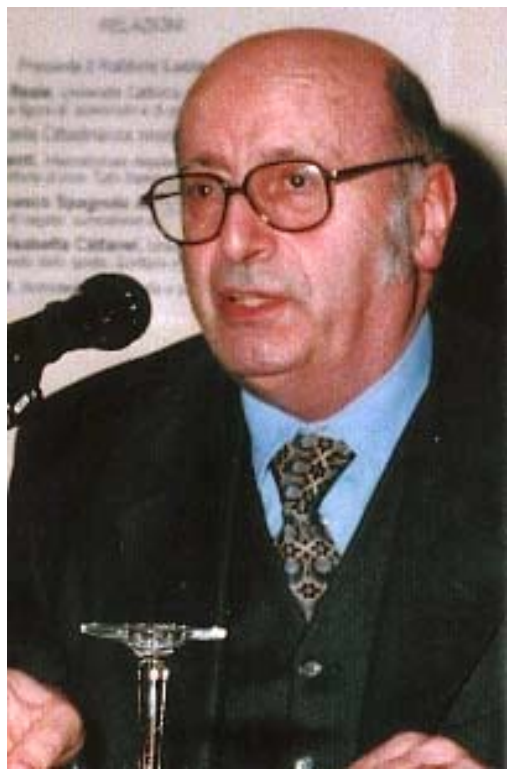

REALE: Mi sono avvicinato alla filosofia fin dal primo incontro che ho avuto con essa nella prima classe del Liceo Classico, che è stato in Italia per anni un vero e proprio modello educativo, creato dal grande Giovanni Gentile. Ciò che mi ha subito colpito è stato l'impatto con la diversità dei sistemi che si sono succeduti nella storia. Ho compreso, di conseguenza, la ragione per cui dei grandi ingegni possano maturare idee anche opposte e sostenerle in maniera brillante, proprio sulla base di ciò che dice Platone. La $<<$ sofia $>>$ è possesso degli dèi e non degli uomini.

1 Intervista condotta da Dennys Garcia Xavier, dottorando in Storia della Filosofia, Università degli Studi di Macerata (Italia), sotto la guida del prof. Maurizio Migliori. Borsista della "Coordenação de Aperfeiçoamento de Pessoal de Nível Superior" (CAPES). E-mail: dennysgx@gmail.com 
Propria degli uomini è invece la $<<$ filosofia $>>$, l'amore e la ricerca della $<<$ sofia $>>$. L'uomo è un homo viator, e ciò che può fare è appunto ricercare il Vero, pur non trovandolo mai nella sua interezza.

Di conseguenza, ho scelto di specializzarmi non in filosofia teoretica e sistematica, ma nella storia della filosofia, per scoprire i vari modi nei quali l'uomo ha costruito i vari sistemi, nel suo continuo viaggio sulla strada della Verità.

XAVIER: Parte del Suo percorso formativo è stato fatto in Germania. Qual è l'importanza di un periodo di studi all'estero? Crede che ora, anche con l'avvento di internet, con la diffusione dei convegni internazionali, i lessici digitali e tutte le risorse tecnologiche disponibili questo tipo di esperienza sia ancora determinante?

REALE: I miei anni passati in Germania, a Marburg e a München, sono stati per me essenziali, non solo dal punto di vista dell'apprendimento di un solido metodo scientifico (allora la Germania era al primo posto negli studi sul pensiero antico), ma anche nella mia formazione spirituale. Ricordo che allora (19541957) i rapporti dei Tedeschi con gli Italiani erano assai tesi, in quanto gli Italiani (per le vicende connesse con la Seconda Guerra Mondiale e le sue conclusioni) venivano considerati, se non dei traditori, quantomeno uomini non affidabili.

Ricordo un particolare assai significativo. In quanto già laureato, ero ammesso a tavola con i professori. Gli studenti che arrivavano in ritardo, dovevano chiedere al capo il permesso di consumare il pasto. Se erano meno di cinque minuti, in genere il permesso veniva concesso, altrimenti no. Inoltre, tutti i colleghi, quando lo studente ritardatario si recava al suo posto, dovevano esprimere la loro disapprovazione, strisciando i piedi a terra in modo adeguato. Degli Italiani, a tavola, in mia presenza, parlavano spesso molto male. E un giorno, dopo che uno dei professori aveva sorpassato i limiti della decenza nelle sue critiche, io ho chiesto la parola e ho detto: << voi Tedeschi parlate così male di noi Italiani; ma quante volte siete venuti in Italia e ci avete mangiato?>>. E la 
risposta è stata terribile: << sì, vi abbiamo spesso mangiati, ma voi ci avete guastato lo stomaco! $>>$.

Devo però dire che, dopo essere stato sottoposto a varie prove, il direttore $\mathrm{mi}$ ha dato la chiave della biblioteca, in modo che, all'occorrenza, avrei potuto consultare libri anche fuori orario.

Sulla base di ciò che ho imparato dai Tedeschi in quegli anni, ho potuto intrecciare eccellenti rapporti con Hans Krämer, Konrad Gaiser, Werner Beierwaltes, Thomas Szlezàk e da ultimo anche con Hans-Georg Gadamer.

Quanto a Internet e ai vari strumenti multimediali sono cose straordinarie che semplificano e risolvono una gran quantità di problemi, ma non insegnano ad aver rapporto con gli uomini, e non fanno crescere l'uomo in quanto uomo.

XAVIER: Lei conosce varie lingue. Quando ha cominciato a studiarle? Qual è la loro importanza per lo studio della filosofia?

REALE: Una lingua non è soltanto uno strumento asettico di comunicazione, ma è espressione di una cultura con tutte le sue implicazioni e conseguenze. Perciò, con la sola lingua madre, lo studioso rimane sotto certi aspetti un isolato. Ed è ciò che capita, per esempio, a certi studiosi dell' area culturale della lingua inglese. Siccome l'inglese è ormai lingua universale che i più capiscono, molti di tali studiosi tralasciano di studiare le lingue, con tutte le conseguenze ben immaginabili. Io ho iniziato a studiare le lingue dal ginnasio e non ho mai smesso di cimentarmi soprattutto con il francese e con il tedesco.

XAVIER: Lei è co-autore e divulgatore di un nuovo paradigma interpretativo del pensiero platonico (la cosiddetta scuola di TubingaMilano) che mette in gioco le cosiddette "Dottrine non-scritte" di Platone. Per quali ragioni ha aderito a questo nuovo modo di leggere Platone?

REALE: Il mio impatto con l'interpretazione di Platone della Scuola di Tubinga è avvenuto dopo la lettura del grosso libro di H. Krämer, Areté bei Platon und Aristoteles. Il libro capovolgeva la tesi di $\mathrm{H}$. 
Cherniss, allora molto diffusa in Italia (nel 1974 era anche uscita la traduzione italiana del libro sintetico di Cherniss, L'enigma dell'Accademia Antica). A quel punto ho chiesto direttamente a Krämer se accettasse di scrivere un libro sintetico, leggibile non solo dagli specialisti di filosofia antica ma da tutti i cultori di filosofia, sulla interpretazione della Scuola di Tubinga, che avrei io stesso tradotto. Krämer ha subito accettato e ha scritto il volume Platone e $i$ fondamenti della metafisica. Da rigoroso scienziato quale è, ha voluto controllare direttamente con me ogni parola della traduzione. E in questi incontri (in Italia e in Germania) io chiedevo continuamente che mi venissero fornite le prove dei vari asserti, sulla base di precisi documenti. E i documenti via via richiamatimi si sono dimostrati tanto precisi (e sotto molti aspetti indiscutibili), che io ho pregato di presentarli in maniera sistematica alla fine del volume (con testo greco e traduzione a fronte). Di conseguenza, mi sono reso conto della insostenibilità della tesi tradizionale della <<autarchia >> dei dialoghi e della impossibilità di intendere Platone leggendo solo i suoi scritti e rifiutando di esaminare a fondo anche la tradizione indiretta, da Platone stesso giustificata nelle autotestimonianze del finale del Fedro e dell'excursus della Lettera VII. Di conseguenza, ho imboccato tale via e ho proceduto in modo sistematico a percorrerla sino in fondo.

XAVIER: Si aspettava la resistenza dei ricercatori nei confronti di questo nuovo paradigma interpretativo? A che cosa si deve, secondo Lei, tale resistenza?

REALE: La resistenza che si è verificata nei confronti della tesi della Scuola di Tubinga, che io ho presentato come un vero e proprio paradigma ermeneutico alternativo a quello formulato in età moderna a partire da Schleiermacher, e ho contribuito a completare soprattutto su alcuni punti, è proprio quella che Kuhn ha dimostrato verificarsi tutte le volte che viene proposto, nell'ambito delle varie ricerche scientifiche, un nuovo paradigma alternativo a quello predominante.

Faccio un esempio particolarmente eloquente. Quando ho pubblicato la prima edizione completa del mio libro Per una nuova 
interpretazione di Platone, i due professori di storia della filosofia antica universitari più influenti dal punto di vista accademico, mi invitarono a pranzo, per dirmi che avrei dovuto mandare l'opera al macero, perché avrebbero proibito l'adozione della medesima, in quanto <<inquinava>> il puro pensiero di Platone.

Ma l'esito dell'opera giudica i giudicanti in modo irreversibile. Nel 2003 ho pubblicato la ventunesima edizione, e nel frattempo è stata tradotta in tedesco, in inglese, in portoghese, in spagnolo, in ceco; inoltre è già in avanzata elaborazione la traduzione romena.

I più favorevoli alla nuova interpretazione sono i giovani; però spesso sono condizionati dai loro maestri, alcuni dei quali fanno di tutto per distoglierli da essa, anche con metodi ben poco scientifici.

XAVIER: Facendo un piccolo esercizio di "futurologia", a Suo parere, il Nuovo Paradigma della scuola di Tubinga-Milano si imporrà al mondo dell'accademia come un giorno accadde a quello di Schleiermacher? Qual è il grado attuale di accettazione del Nuovo Paradigma tra i ricercatori secondo Lei?

REALE: Dopo aver scritto Per una nuova interpretazione di Platone ho scritto anche Platone: Alla ricerca della sapienza segreta, uscito nel 1998 (con tre edizioni nello stesso anno) e già passato (per il successo avuto) in una collana di tascabili.

Io credo che il nuovo paradigma, come dimostro in questo secondo libro, riceve cospicue conferme dalle ricerche sulle tecnologie della comunicazione nel mondo antico. Il predominio della cultura della scrittura e il superamento della cultura dell'oralità avveniva esattamente nell'arco di tempo della vita di Platone. E proprio nella comprensione della dinamica di questa rivoluzione culturale si riesce a capire la posizione presa da Platone e i rapporti da lui assunti nei confronti della scrittura e dell'oralità.

XAVIER: Alcuni studiosi La accusano di proporre un'interpretazione "ipermetafisica" di Platone a causa del Suo rapporto con la religione cattolica. Come risponde ad accuse di questa natura? Si può dire che questa influenza religiosa esiste realmente nella Sua lettura di Platone? 
REALE: Devo dire che coloro che sostengono tale tesi non conoscono né il cattolicesimo nella sua vera natura, né il modo in cui lo vivo, come vero credente. Confondono la fede di un cattolico con una ideologia. La mia fede non entra in ballo su questioni scientifiche, quando le tratto in maniera rigorosa, anche per il fatto che non considero che la scienza abbia i titoli giusti per invadere il campo della fede, per i suoi limiti strutturali. La mia opinione riguardo a tale problema è quella espressa dal filosofo italiano Luigi Pareyson (Ontologia della libertà, 1995), ossia che legare Dio e la fede in Dio con una filosofia (per grande che essa sia), significa cadere in una forma di antropomorfismo (sia pure assai raffinato): $<<$ Concepire Dio in termini concettuali significa definirlo in base a categorie elaborate dalla mente umana e attribuirgli proprietà che direttamente o indirettamente ineriscono all'uomo, sia pure estremamente raffinate e astratte, e sia pure pensate in senso eminente ed elevate al vertice. In tal senso concepire Dio come Essere, Principio, Causa, Pensiero, Ragione, Volontà, Persona, Bontà, Provvidenza, e così via, è pur sempre un kat'anthropon legein, che conferiscono a tali concezioni della divinità un carattere sostanzialmente, anche se larvatamente, antropomorfico $>>$.

La mia fede religiosa è al di sopra della mia interpretazione di Platone, proprio dal punto di vista strutturale, in quanto occupa uno spazio che è al di là della scienza.

XAVIER: Professore, qual è l'importanza della ricerca nella storia della filosofia antica all'interno di un dipartimento di filosofia? Gli altri momenti storici del pensiero filosofico possono essere intesi in modo adeguato senza una corretta comprensione dell'antichità?

REALE: Io penso che l'importanza della storia della filosofia antica nell' ambito di un dipartimento di filosofia e quindi di una laurea in filosofia sia assolutamente essenziale. I Greci ci hanno infatti dato il concetto stesso di filosofia e molti dei concetti fondamentali che la filosofia moderna e anche contemporanea usa derivano dai concetti creati dal pensiero ellenico.

Senza la filosofia antica mancano le basi stesse del filosofare. 
Martin Heidegger diceva che la filosofia in Grecia è nata grande. Semmai, potremmo dire, qualche volta (soprattutto in certe tendenze di oggi) è rimpicciolita.

Cito un caso particolare veramente emblematico. J. Habermas sostiene la tesi secondo cui oggi la filosofia non è più autorizzata a intervenire in modo diretto nei problemi morali, ossia proprio nei grandi problemi, e scrive: <<Proprio nelle questioni per noi più rilevanti, la filosofia si ritira su una sorta di metalivello. Essa si limita a indagare le caratteristiche dei processi di autocomprensione, facendo astrazione dai loro contenuti. Ma che obiezioni potremmo mai sollevare contro questa astensione ben giustificata? >>. Ma, facendo questo, si toglie alla filosofia il suo spessore, e la si dissolve. I Greci costituiscono l'antidoto curativo di questo male. Ed è un antidoto fortissimo. Solo chi ha compreso la filosofia antica può difendersi da questi mali della riduzione della filosofia a metodologia in tutte le sue varie forme.

XAVIER: Gli studi sulla filosofia antica in America del Sud negli ultimi anni si sono sviluppati grazie all'impegno di diversi professori appassionati e dediti ai loro studi e allo stretto contatto con ricercatori di altri continenti. Secondo Lei, cosa potrebbero fare per accelerare questa evoluzione?

REALE: Il modo di accelerare la diffusione dello studio della filosofia antica nell' America del Sud è uno solo: quello dell'impegno e della passione con cui la diffusione, come Lei dice, è iniziata. Senza impegno e senza passione non si conclude nulla.

XAVIER: Le Sue opere riscuotono un grande successo editoriale e questo è un fatto particolare in un mondo cosi ristretto come quello della ricerca filosofica. A che cosa si deve questo successo?

REALE: Io per primo sono stupefatto del successo che stanno avendo le mie opere. Sono tradotte in tedesco, in inglese, in francese, in spagnolo, in portoghese, in russo, in polacco, in croato, in ucraino, in romeno, in ceco, e sono in corso di traduzione anche in 
altre lingue. Mi ha commosso, da ultimo, il fatto che i vari volumi della mia Storia della Filosofia Antica siano stati tradotti addirittura in sloveno (e la Slovenia è una nazione di pochi abitanti).

Le ragioni di tale successo mi sono state suggerite dalla traduttrice russa (che ha tradotto in quattro volumi l'opera Il pensiero occidentale, che ho scritto con Dario Antiseri) e dal traduttore polacco (che ha tradotto tutti i volumi della Storia della Filosofia Antica). Alla mia domanda: <<ma perché fate un lavoro così complesso e faticoso che porta via molti anni alla vostra vita?>>, mi hanno dato la stessa risposta: <<cerchiamo le radici da cui siamo nati, e che per molti decenni sono state dimenticate $>>$. Il traduttore polacco ha aggiunto anche questa ulteriore risposta: $<<$ Il marxismo ha creato nelle anime un vuoto totale; per uscire da tale situazione chi ha una fede imbocca quella strada, chi non ha una fede cerca nei classici idee forti politicamente non compromesse>>. La traduttrice romena della mia opera Saggezza Antica: terapia per i mali dell'uomo di oggi mi ha espresso un concetto analogo, dicendomi: <<Affronto questa fatica cercando di dare ai giovani romeni un forte aiuto con la riscoperta dei valori del pensiero classico, in quanto molti di essi sono passati da "nichilismo marxista" al "nichilismo consumista" >>. Non sono le mie idee ad avere successo, ma le idee dei classici, presentate da uno come me che crede nel loro valore.

Il pittore Zeusi, alla richiesta del perché fosse così lento nel comporre le sue opere e non si stancasse di perfezionarle, rispose: $<<$ perché io dipingo l'eterno >>. Tucidide nella sua opera storica dice la stessa cosa; afferma, infatti, che ciò che egli presenta in essa costituisce $<<$ un possesso per il sempre $>>$, e Platone diceva che il filosofo è colui che sa guardare l'eterno. E io sono profondamente convinto che le opere filosofiche degli antichi siano davvero un possesso per il sempre. E i lettori che mi seguono ritengo che pensino la stessa cosa (Platone è oggi il filosofo più venduto, e non solo in Occidente).

XAVIER: Un'ultima domanda: nella prefazione della traduzione italiana dei dialoghi platonici "Platone: Tutti gli Scritti" Lei dice di offrire un 
libro che costituisce un'occasione di riflessione a tutti gli uomini di cultura che credono sia necessario che lo spirito umano si cibi dei cibi migliori. Tra $i$ buoni cibi che Lei ha mangiato nella Sua vita dedicata alla filosofia e alla cultura in generale quale è stato il più squisito?

REALE: Il cibo migliore, naturalmente, è stato quello offertomi da Platone. Ma, a non lontana distanza devo ricordare la Metafisica di Aristotele, cui ho dedicato ben dieci anni di lavoro. Ma cibi squisiti ho trovato anche nei poeti. Hans-Georg Gadamer, nel giorno in cui gli ho fatto l'ultima intervista, mi diceva che egli ha imparato talvolta più dai poeti che da certi filosofi anche di gran nome. E io sono dello stesso parere. Oltre ai tre grandi poeti - Dante, Shakespeare, Goethe - leggo spesso Rilke e Eliot...e con grande frutto! 